\title{
Evaluating the return on investment of tobacco control intervention in Indonesia
}

\author{
Susi Ari Kristina ${ }^{*}$, Tri Murti Andayani², Anna Wahyuni' ${ }^{1}$, Hardika Aditama1 \\ ${ }_{1}$ Department of Pharmaceutics, Faculty of Pharmacy, Universitas Gadjah Mada, Yogyakarta, Indonesia \\ 2 Department of Pharmacology and Clinical Pharmacy, Universitas Gadjah Mada, Yogyakarta, Indonesia
}

\begin{abstract}
In Indonesia, smoking is the leading cause of noncommunicable diseases. Tobacco control strategies will reduce the burden of smoking. The aim of this study is to determine the return on investment (ROI) of tobacco control program in Indonesia. The OneHealth tool was used to estimate the economic benefits of tobacco prevention interventions. We calculated the resources and costs of selected packages using a five-year time period 2020-2024. Demographic and unit cost data are used to run the model. The economic benefits were described as the amount of lives saved and healthy life years earned. The monetary value of productivity gains is divided by the costs of the intervention to calculate the Return on Investment (ROI). An estimated 1,904 lives will be saved and 30,882 healthy life years will be restored. Intervention of excise taxes contribute to the majority of averted deaths (597 deaths) and mass media campaigns responsible to the life years gained (10,452 life years). The overall economic benefits (13.86 million USD) greatly outweigh the costs over a five-year period (8.5 million USD). The ROI of the chosen packages will be 1.87 , indicating that the intervention packages would result in significant health and economic benefits. Overall, the findings suggest that investing in a tobacco control program will help the Indonesian government escape substantial direct and indirect costs. The findings aided in the implementation of the strategic plan and added to the evidence base for better budgeting, resource allocation plans, and overall financial planning in the public sector.
\end{abstract}

\section{Keywords:}

Return on investment, Tobacco control, OneHeatlh Tool, Indonesia

\section{INTRODUCTION}

Smoking is prevalent in Indonesia. There are about a hundred million smokers in Indonesia, and approximately $63 \%$ of men and $5 \%$ of women were active smokers $^{1,2}$. According to a 2018 national survey, smoking prevalence among youth aged 10 to 18 years old was $9.1 \%^{2}$ with nearly 2 million cases of tobacco-related non-communicable diseases (NCDs) and 230,862 tobaccorelated NCDs deaths in 2015, Indonesia lost US\$ 45.9 billion as a result of tobacco use $^{3}$. In Indonesia, the combined revenues of the six largest tobacco companies exceeded USD 346 billion, accounting for 38\% of Indonesia's Gross National Income ${ }^{3}$.

If Indonesia is to curb the growing epidemic and reap the benefits of the expected demographic dividend, the government must convey its commitment to tobacco control initiatives. To date, government has made several progress with adopting smoke-free regulations and limiting tobacco advertising ${ }^{1}$. At the national level, a $40 \%$ pictorial health warning has been introduced, but there has been no notable advancement due to lack of enforcement ${ }^{4}$. Indonesia is the only country in the broadcasts cigarette advertisement on $\mathrm{TV}$, and among the lowest cigarette tax in the world ${ }^{5}$. The size of the cigarette market in Indonesia may impede the progress of tobacco control $^{6}$.

Evidence-based smoking prevention measures, that can reduce the future burden of smoking need to be prioritized $^{7}$. In order to achieve the objectives of health for all, the health ministry intends to expand the essential health-care interventions toward preventive and control

*Corresponding author:

*Susi Ari Kristina susiari_k@ugm.ac.id 
interventions ${ }^{6}$. Although several interventions have already had high impact, the prevention intervention services currently have low coverage ${ }^{8}$. Governments must consider the costs and resource consequences of potential policies when developing health programs. Decision-makers may assess the tobacco control plan's viability and affordability by estimating the resources needed for implementation. Cost estimation help the health-care system allocate limited budget. Such projection also guide decisions on how much money should be allocated to the health sector versus other public sectors 9 .

However, only a limited literature explains how to conduct economic analysis on national-level program based on health-sector resource needs and priorities. Some developing countries chose the OneHealth method, developed by World Health Organization (WHO), which was designed to estimate resource needs for health programs, and aimed to inform national strategic health planning ${ }^{10}$. The objective of this research is to calculate the return on investment (ROI) associated with the implementation for priority of tobacco control policy interventions. We explain how we used the OneHealth tool to inform the strategy's implementation and prioritization, as well as the cost of implementing the strategies and the availability of sufficient financial resources to cover costs. The materials and methods section covering intervention selection, cost analysis of interventions, evaluating and valuing the health benefits describes the steps involved in conducting a return on investment analysis of tobacco control interventions.

\section{MATERIALS AND METHODS}

There are five main methodological steps in the economic analysis component of the investment case. Details on each step are provided below.

\subsection{Intervention Selection}

The types of tobacco control interventions were chosen based on a review from experienced staffs in the Ministry of Health and the Ministry of Finance. In collaboration with the Ministry of Health, established baseline levels for the interventions and scale-up targets were fixed. Tobacco control interventions were included based on the following criteria: (1) the WHO Global Action Plan's list of "best buys" (or cost-effective interventions), (2) ongoing country priorities and initiatives, and (3) available interventions in the analytical models used (WHO OneHealth Tool software and WHO Costing Tool) ${ }^{11}$. WHO OneHealth Tool software is an approach to evaluate strategic health planning, costing and health impact analysis in low-middle income countries. Table 1 summarizes the types of interventions considered in this investment case, as well as their target and baseline levels.

\subsection{Cost Analysis of Interventions}

The WHOCosting tool was used to estimate the costs of policy interventions. The OneHealth Tool (OHT) calculates the cost of policy interventions using an ingredients-based approach. WHO experts identified and quantified each resource required to implement and enforce policies as part of this tool. The analysis was conducted in collaboration with the Indonesian Ministry of Health and used Indonesian-specific costs for materials and human resources.

\subsection{Evaluating the Health Benefits}

The OneHealth Tool (OHT) was used to model the number of lives saved and healthy years gained over a 5-year period in order to assess the benefits of implementing or scaling up health interventions. OHT is fully

Table 1. Details of the specific tobacco control interventions along with their respective baselines and targets.

\begin{tabular}{lll}
\hline \multicolumn{1}{c}{ Tobacco control intervention } & \multicolumn{1}{c}{ Baseline } & \multicolumn{1}{c}{ Target } \\
\hline $\begin{array}{l}\text { Increase excise taxes and prices on tobacco } \\
\text { products }\end{array}$ & $\begin{array}{l}\text { Excise taxes equal to 35\% of the retail price } \\
\text { of tobacco products }\end{array}$ & $\begin{array}{l}\text { Excise taxes equal to } 70 \% \text { of the retail price } \\
\text { of the tobacco products }\end{array}$ \\
\hline $\begin{array}{l}\text { Bans on tobacco advertising, promotion, } \\
\text { and sponsorship }\end{array}$ & $\begin{array}{l}\text { No bans on advertisement in media, as well } \\
\text { as direct and indirect advertising }\end{array}$ & $\begin{array}{l}\text { Ban on all forms of advertisement, direct } \\
\text { and indirect advertising }\end{array}$ \\
\hline $\begin{array}{l}\text { Eliminate exposure to secondhand smoking } \\
\text { in all public places }\end{array}$ & $\begin{array}{l}\text { Smoking is banned in all public places, but } \\
\text { the ban is not well enforced in hotels, } \\
\text { restaurants }\end{array}$ & $\begin{array}{l}\text { Smoking banned in all public places, cafes } \\
\text { and hotels are compliant }\end{array}$ \\
\hline $\begin{array}{l}\text { Implement plain graphic health warnings on } \\
\text { all tobacco packages }\end{array}$ & $\begin{array}{l}\text { Graphic health warnings covering 40\% of } \\
\text { the package is required on all tobacco } \\
\text { product packages. Plain packaging is not } \\
\text { mandated for tobacco products. }\end{array}$ & $\begin{array}{l}\text { Plain packaging is mandated for tobacco } \\
\text { products }{ }^{4} \text {. }\end{array}$ \\
\hline $\begin{array}{l}\text { Implement mass media campaigns about } \\
\text { harms of tobacco and smoking }\end{array}$ & No education using mass media campaign \\
\hline $\begin{array}{l}{ }^{1} \text { Target set in accordance with Guidelines for Implementation of Article } 6 \text { of Framework Convention on Tobacco } \\
\text { Control (FCTC) }\end{array}$ & $\begin{array}{l}\text { Mass media campaign in place with all } \\
\text { recommended characteristics }\end{array}$ \\
$\begin{array}{l}{ }^{2} \text { Target set in accordance with Article 13 of FCTC } \\
{ }^{3} \text { Target set in accordance with Article } 8 \text { of FCTC }\end{array}$ & \\
${ }^{4}$ Target set in accordance with Article 11 of FCTC &
\end{tabular}


customizable, which means that users can enter data on a country's health services, local costs, intervention coverage levels, prevalence and incidence rates, and demographic composition ${ }^{12}$. All Indonesian inputs include all cost components of proposed tobacco interventions were entered into OHT, which was then used in conjunction with the Tool's existing cost and benefit modules to calculate the benefits of interventions.

\subsection{Valuing the benefits}

The predicted health benefits-avoided deaths and increased life years are converted into economic gains by modeling the increased labor productivity resulting from better health. Labor participation rate was retrieved from the National Statistics Database 2020, which indicated a workforce participation rate of 76 percent. The number of people who avoided morbidity times the proportion who would participate in the labor force (and be gainfully employed) times the net gain in job productivity (GDP per worker) from avoided morbidity was used to measure productivity gains from preventing presenteeism (missed days of work and reduced activity while at work) caused by tobacco use. The valuation details are run in economic modeling, which results in a score for the return on investment of each tobacco control intervention.

\subsection{Return on investment (ROI)}

Return on investment (ROI) analysis quantifies an investment's efficiency. If the net financial benefit from an investment exceeds the cost of making the investment $(\mathrm{ROI}>1)$, the investment is successful. The $\mathrm{ROI}$ of chosen interventions is measured in this exercise by dividing the monetary value of productivity gains by the costs of scaling up or introducing the intervention.

\section{RESULTS}

Implementing the intervention packages would result in significant health and economic benefits. This analysis summarizes the health benefits, economic benefits, and ROI analysis of the interventions as shown in Table 2 and Table 3 . All five packages of interventions have a positive return on investment from the five-year time horizon.

The results indicate that over a five-year period, an estimated 1,904 lives will be saved and 30,882 healthy life years will be restored to the Indonesian population. The estimated health impact of each intervention package is summarized in Table 2. Increase excise taxes contribute to the majority of averted deaths (597 deaths) and implement mass media campaigns responsible to the most healthy life years gained (10,452 life years).

Monetizing the health benefits in this analysis, results show that these policies will generate a present value of 39.4 million USD five years from now (Figure 1). By way of comparison, Indonesia's current annual GDP is approximately 1.119 trillion USD. As a result, the benefit from implementing the policy package is 3.5 percent of current annual GDP.

When the costs and benefits of each intervention package are compared, the analysis concludes that all five types of interventions are efficient, as the gains from these investments exceed their costs over a fiveyear period (2020-2024).

Table 3 summarizes the return on investment for each of the five packages.

Tobacco intervention through plain graphic health warnings has the highest return on investment at 3.39 , which means that for every dollar invested in this

Table 2. Estimated health benefits and implementation costs by intervention package over a 5-year time horizon.

\section{Intervention package}

Deaths averted

Life years gained

Total 5-year implementation costs (million USD)

\begin{tabular}{lrrr}
\hline Increase excise taxes & 597 & 7,315 & 1,900 \\
\hline Bans on TAPS* & 430 & 4,324 & 1,543 \\
\hline Eliminate exposure to secondhand smoking & 216 & 6,457 & 2,032 \\
\hline Implement plain graphic health warnings & 235 & 2,334 & 756 \\
\hline Implement mass media campaigns & 426 & 10,452 & 2,421 \\
\hline Total & $\mathbf{1 , 9 0 4}$ & $\mathbf{3 0 , 8 8 2}$ & $\mathbf{8 , 6 5 2}$ \\
\hline
\end{tabular}

*TAPS: tobacco advertising, promotion, and sponsorship

Table 3. Return on investment of each tobacco control intervention.

\begin{tabular}{lccc}
\hline \multicolumn{1}{c}{ Intervention } & Benefit (million USD) & Cost (million USD) & ROI \\
\hline Increase excise taxes & 3.45 & 1.9 & 1.82 \\
\hline Bans on TAPS & 2.34 & 1.5 & 1.56 \\
\hline Eliminate exposure to secondhand smoking & 2.49 & 2.0 & 1.25 \\
\hline Implement plain graphic health warnings & 2.37 & 0.7 & 3.39 \\
\hline Implement mass media campaign & 3.21 & 2.4 & 1.34 \\
\hline Total & $\mathbf{1 3 . 8 6}$ & $\mathbf{8 . 5}$ & $\mathbf{1 . 8 7}$ \\
\hline
\end{tabular}




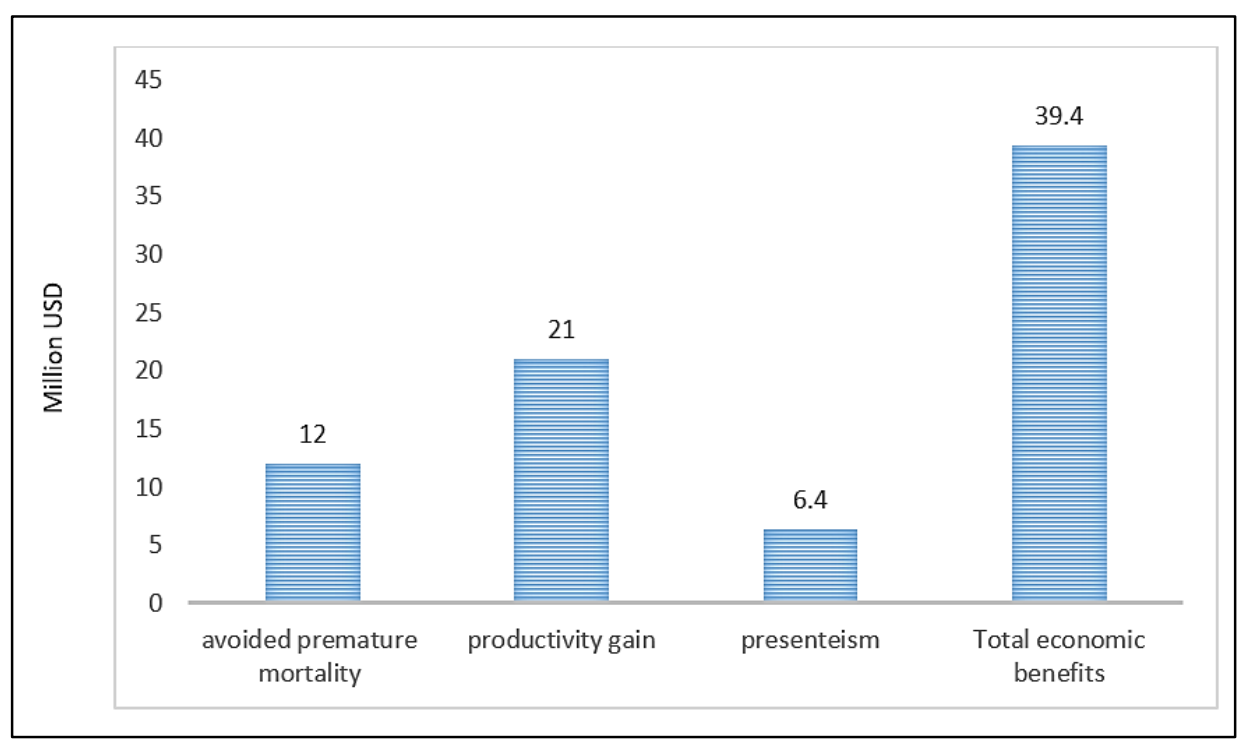

Figure 1. Recovered economic output from implementing tobacco control interventions based on OneHealth modeling.

program, 2.37 USD will be returned. Increase excise taxes comes in second place with a return on investment of 1.82, followed by the TAPS package with a return on investment of 1.56 .

Additionally, investing in all five packages is a cost-effective investment. The overall economic benefits (13.86 million USD) greatly outweigh the costs over a 5 -year period ( 8.5 million USD). The ROI of the chosen packages will be 1.87 at the end of the 5-year period. Indicating that the "break-even" point for tobacco control packages will be reached in less than five years, according to the analysis.

\section{DISCUSSION}

In line with global evidence and the WHO Global Action Plan for the Prevention and Control of Noncommunicable Diseases (NCDs) 2013-2020 ${ }^{9}$, the findings indicate that there is an opportunity to reduce the burden of tobacco-related diseases through preventative actions targeting behavioral risk factors for NCDs. In terms of public interventions, it is critical to invest more in strengthening the health system in order to ensure that all tobacco control efforts are cost effective and generate a positive return on investment. Nevertheless, the findings indicate that some of the most cost-effective investments occur outside direct jurisdiction of the Ministry of Health, include raising tobacco taxes and enacting restrictions on tobacco advertising. This demonstrates the critical importance of involving stakeholders outside the health sector in policy development, as well as the importance of developing comprehensive and coherent policies across government sectors.

NCDs as the leading cause of morbidity and mortality in Indonesia ${ }^{3}$, continue to pose a significant and growing threat. The findings of this analysis indicate that investments to combat the rise in tobacco use in
Indonesia can effectively reduce the economic burden of NCDs and improve citizens' quality of life. In concrete terms, the findings indicate that Indonesia can mitigate the burden through preventative measures while also ensuring access to treatment for those in greatest need.

Tobacco interventions have ROI, which means that for every dollar invested in tobacco control, 1.87 USD in return is expected. Within the tobacco package, increasing excise taxes has a ROI of 1.82 , followed by prohibitions on tobacco advertising, promotion, and sponsorship with a return on investment of 1.56 . Indonesia can easily expand its tobacco control gains by enforcing existing tobacco legislation, approving the development of a comprehensive tobacco control legislation at the earliest convenience, including the FCTC time-bound commitment to prohibit all forms of tobacco 13-14.

Our modelling did not show a significant effect of smoking restrictions in public places, despite the fact that clear evidence exists to support expected health benefits. This can be explained by the fact that not all implementations are strictly adhered to. Numerous Indonesian communities worked to implement voluntary policies, such as a smoke-free zone in a local community household, prior to the introduction of government policies, thus, the health benefits of protecting workers and the public may have been achieved in part prior to the study period ${ }^{15,16}$.

Policymakers who are convinced of a tobacco control program's effectiveness may still wonder whether the program can be terminated following a period of success. Indeed, recent evidence indicates that when a strong program is eliminated, progress is lost. For instance, Yogyakarta city ran a well-funded program from 2003 to 2012 before discontinuing funding in mid$2013^{15}$. During the period of initial funding, city-level declines in cigarette consumption were greater than 
national declines, but consumption began to increase at a faster rate than the national average following defunding. Separately, Indonesian researchers demonstrated that schools funded by the program, which demonstrated significantly lower smoking initiation rates among youths in intervention than in comparison schools, rebounded after the program was terminated. wiping out the majority of the program's progress in smoking prevention ${ }^{15,17}$. Although programs appear to be costly, our findings indicate that they save money over a five-year horizon.

The OneHealth tool was especially useful for understanding health system budgeting, which, in fact, disease prevention program costs have been underestimated or data have been omitted when measured ${ }^{12}$. The projections also revealed a discrepancy between actual budget allocation and resource needs for various program areas. This information will be used by the health ministry to address funding options including resource mobilization techniques, and to enhance resource distribution based on public health needs.

As Indonesia's economy has grown increasingly, numerous international donors have begun to reduce or withdraw their support for the health sector. Increased government co-financing has been sought by global health programs such as the Gavi, the vaccine alliance. As a result, the government recently raised its expenditure allocation to cover the expenses of the healthcare funds and the availability of essential medicines. Designing co-finance approaches to boost allocative and technological performance in the public health sector would be necessary to ensure sustainable financing of key health programs. The cost analysis discussed here can be used by the health ministry to make evidence-based decisions.

Our analysis had several limitations. Indonesiaspecific prices were undisclosed for the majority of program information. As a result, we employed default prices based on the average cost difference for which Indonesian price data was available. It is critical to acknowledge the limitations of the methodological tools used because they affect the scope of the analysis. The first limitation is that not all of the WHO's Best Buy interventions are programmed in the OneHealth Tool, and thus are not included in the analysis ${ }^{10}$. This is especially relevant for the Indonesian Investment Case, as cancer, chronic respiratory disease, insufficient physical activity, and unhealthy diets are all areas of focus for the Ministry of Health but are not included in the analysis. Policy interventions aimed at reducing physical inactivity and unhealthy diets are particularly high on the Ministry of Health's priority list.

The second significant limitation is that the health impact of selected tobacco control interventions does not account for all of the interventions' health benefits. For example, while the impact of tobacco control policies is measured in terms of averted strokes and ischemic heart disease events, the impact on cancer and chronic respiratory diseases is not. The impact on cardiovascular or diabetes-related complications is considered only for these interventions. This implies that the associated health and economic benefits are grossly understated.

\section{CONCLUSIONS}

Finally, scaling up the recommended package of treatments over the five-year period 2020-2024 will save lives. The costs of achieving these large outcomes will be insignificant in comparison to the benefits. As a result, the prioritized strategies modeled provide a costeffective path to growing Indonesia's economy by $3.5 \%$. Overall, the findings suggest that engaging in tobacco control interventions will help the Indonesian government escape substantial direct and indirect costs. Tobacco control interventions, like robust campaigns, can continue to be funded by policymakers and public health officials.

\section{ACKNOWLEDGEMENT}

We would like to express our gratitude to all members of the Indonesian Ministry of Health expert panel for their contributions to this project. The Ministry of Higher Education has provided us with funding under grant agreement no. 6/E1/KP.PTNBH/2021.

\section{Conflict of interest}

The authors declare that they have no conflict of interest.

\section{Funding}

None to declare.

Ethics approval

None to declare.

Article info:

Received April 9, 2021

Received in revised form July 16, 2021

Accepted July 19, 2021

\section{REFERENCES}

1. Tan YL, Dorotheo U. The tobacco control atlas: ASEAN region, $4^{\text {th }}$ ed. Bangkok: Southeast Asia Tobacco Control Alliance (SEATCA), 2018.

2. Kementerian Kesehatan Republik Indonesia. Hasil Utama Riskesdas 2018. Jakarta: Badan Penelitian dan Pengembangan Kesehatan, 2018.

3. Kristina SA, Endarti D, Wiedyaningsih C, Fahamsya A, Faizah N. Health Care Cost of Noncommunicable Diseases Related to Smoking in Indonesia, 2015. Asia Pac J Pub Health. 2018:1-7.

4. World Health Organization. WHO Report on the Global Tobacco Epidemic. Geneva: World Health Organization, 2017.

5. Heydari G, Chamyani F, Masjedi MR, Fadaizadeh L. Comparison of Tobacco control programs worldwide: A quantitative analysis of the 2015 World Health Organization MPOWER 
report. Int J Prev Med. 2016;7:127.

6. Gupta R, Malhi R, Patthi B, Singla A, Jankiram C, Pandita V, et al. Tracking WHO MPOWER in South East Asian region: An opportunity to promote global tobacco control. J Indian Assoc Public Health Dent. 2016;14:218-23.

7. Amul GGH, Pang TP. The state of Tobacco Control in ASEAN: Framing the Implementation of the FCTC from a Health Systems Perspective. Asia Pac Policy Studies. 2017;5:47-64.

8. John RM, Yadav A, Sinha DN. Smokeless Tobacco taxation: Lessons from Southeast Asia. Indian J Med Res. 2018;148:46-55.

9. World Health Organization. Global action plan for the prevention and control of noncommunicable diseases 2013-2020. Geneva: World Health Organization, 2013.

10. Wong JQ, Haw NJ, Uy J, Bayani DB. Reflections on the use of the World Health Organization's (WHO) OneHealth Tool: implications for health planning in low and middle income countries (LMICs). F1000Res. 2018;7:157.

11. World Health Organization. 'Best Buys' and Other Recommended Interventions for the Prevention and Control of Noncommunicable Diseases Updated (2017) Appendix 3 of the Global Action Plan for the Prevention and Control of Noncommunicable Diseases 2013-2020. Geneva: World Health Organization, 2017.
12. World Health Organization. OneHealth Tool. Geneva: World Health Organization; 2018; Available from: https://www.who.int/ tools/onehealth.

13. Kristina SA, Satibi S, Permitasari NL. National Burden of Cancers Attributable to Secondhand Smoking in Indonesia. Asian Pac J Cancer Prev. 2018;19(7):1951-55.

14. Kristina SA, Permitasari NPAL, Krisnadewi KI, Santosa KA. Incidence and Mortality of Cancers Related to Secondhand Smoking in Southeast Asia Countries. Asian Pac J Cancer Prev. 2019;20(3):971-6.

15. Kristina SA, Thavorncharoensap M, Pongcharoensuk P, Prabandari YS. Impact of Smoking Cessation Training for Community Pharmacists in Indonesia. Asian Pac J Cancer Prev. 2015;16(8): 3319-23.

16. Levy DT, Huang AT, Havumaki JS, Meza R. The role of public policies in reducing smoking prevalence: results from the Michigan SimSmoke tobacco policy simulation model. Cancer Causes Control. 2016;27:615-25.

17. Stenberg K, Rajan D. Estimating cost implications of a national health policy, strategy or plan. In: Strategizing national health in the 21st century: a handbook. Geneva: World Health Organization, 2016. 